\title{
Factors affecting the prognosis of small hepatocellular carcinoma in Taiwanese patients following hepatic resection
}

\author{
Chih-Jan Ko MD¹, Su-Yu Chien MS², Chen-Te Chou MD PhD², Li-Sheng Chen PhD ${ }^{4}$, \\ Mei-Ling Chen $\mathrm{MD}^{5}$, Yao-Li Chen $\mathrm{MD}^{1,6}$
}

\begin{abstract}
C-J Ko, S-Y Chien, C-T Chou, L-S Chen, M-L Chen, Y-L Chen. Factors affecting the prognosis of small hepatocellular carcinoma in Taiwanese patients following hepatic resection. Can J Gastroenterol 2011;25(9):485-491.
\end{abstract}

BACKGROUND: Small hepatocellular carcinoma (HCC) affects millions of individuals worldwide. Surveillance of high-risk patients increases the early detection of small HCC.

OBJECTIVE: To identify prognostic factors affecting the overall survival (OS) and recurrence-free survival (RFS) of patients with small HCC.

METHODS: The present prospective study enrolled 140 Taiwanese patients with stage I or stage II small HCC. Clinical parameters of interest included operation type, tumour size, tumour histology, ChildPugh class, presence of hepatitis B surface antigen and liver cirrhosis, hepatitis C status, alpha-fetoprotein, total bilirubin and serum albumin levels, and administration of antiviral and salvage therapies.

RESULTS: Tumour size correlated significantly with poorer OS in patients with stage I small HCC $(\mathrm{P}=0.014)$; however, patients with stage II small HCC experienced a significantly poorer RFS $(\mathrm{P}=0.033)$. OS rates did not differ significantly between patients with stage I and stage II small HCC. Tumour margins, tumour histology and cirrhosis did not significantly affect OS or RFS $(\mathrm{P}>0.05)$.

DISCUSSION: Increasing tumour size has generally been associated with poorer prognoses in cases of HCC. The present study verified the relationship between small HCC tumour size and OS; however, a reduction in OS with increasing tumour size was demonstrated for patients with stage I - but not for stage II - small HCC.

CONCLUSION: Patients with stage II small HCC may benefit from aggressive surveillance for tumour recurrence and appropriate salvage treatment. Further studies are needed for additional stratification of stage I patients to identify those at increased risk of death.

Key Words: Prognosis; Small hepatocellular carcinoma; Tumour size

L epatocellular carcinoma (HCC) represents the fifth most com1 mon cancer worldwide, and is the most common cancer diagnosed in Taiwan $(1,2)$. According to the International Journal of Cancer, liver cancer accounted for nearly 700,000 deaths worldwide in 2008 (3). Liver cirrhosis, particularly as a consequence of hepatitis B virus (HBV) and hepatitis $\mathrm{C}$ virus (HCV) infections, is recognized as the most common risk factor for the development of HCC (4). Other factors associated with HCC include alcoholic liver disease, nonalcoholic steatohepatitis, obesity and diabetes (5).

Routine screening of high-risk patients (those with cirrhosis and those with HBV and/or HCV) have been shown to increase survival rates. Chen et al (6) demonstrated a $24 \%$ reduction in HCC mortality for high-risk patients using blood tests (including those for HBV surface antigen [HBsAg], HCV antibody [anti$\mathrm{HCV}]$, alanine aminotransferase and alpha-fetoprotein [AFP]) and

\author{
Les facteurs qui influent sur le pronostic du petit \\ carcinome hépatocellulaire chez des patients \\ taïwanais après une résection hépatique
}

\begin{abstract}
HISTORIQUE : Des millions de personnes dans le monde présentent un petit carcinome hépatocellulaire $(\mathrm{CHC})$. La surveillance des patients à haut risque accroît le dépistage précoce des petits $\mathrm{CHC}$.

OBJECTIF : Déterminer les facteurs pronostiques influant sur la survie globale (SG) et la survie sans récurrence (SSR) des patients ayant un petit CHC.

MÉTHODOLOGIE : La présente étude prospective portait sur 140 patients taïwanais atteints d'un petit $\mathrm{CHC}$ de stade I ou II. Les paramètres cliniques d'intérêt incluaient le type d'opération, la dimension de la tumeur, l'histologie de la tumeur, la catégorie de Child-Pugh, la présence de l'antigène de surface de l'hépatite $B$ et la cirrhose du foie, la présence d'hépatite $\mathrm{C}$, les taux d'alpha-fœetoprotéine, de bilirubine totale et d'albumine sérique, ainsi que l'administration d'antiviraux et de thérapies de sauvetage. RÉSULTATS : La dimension de la tumeur était corrélée de manière significative à une moins longue $\mathrm{SG}$ chez les patients ayant un petit $\mathrm{CHC}$ de stade $\mathrm{I}$ $(\mathrm{P}=0,014)$, mais les patients ayant un petit $\mathrm{CHC}$ de stade II présentaient une SSR beaucoup plus courte $(\mathrm{P}=0,033)$. Les taux de $\mathrm{SG}$ ne différaient pas considérablement entre les patients atteints d'un petit $\mathrm{CHC}$ de stade I et ceux en ayant un de stade II. Les marges des tumeurs, l'histologie des tumeurs et la cirrhose n'avaient pas d'incidence significative sur la SG ou la SSR $(P>0,05)$.
\end{abstract}

EXPOSÉ : La dimension croissante de la tumeur s'associe généralement à des pronostics plus sombres dans les cas de $\mathrm{CHC}$. La présente étude a vérifié le lien entre la petite dimension du $\mathrm{CHC}$ et la SG, mais a démontré une réduction de SG parallèle à l'augmentation de la dimension de la tumeur chez les patients ayant un petit CHC de stade I, mais pas de stade II.

CONCLUSION : Les patients atteints d'un petit $\mathrm{CHC}$ de stade II peuvent profiter d'une surveillance agressive des récurrences tumorales et d'une thérapie de sauvetage pertinente. D'autres études s'imposent pour mieux stratifier les patients atteints de la maladie de stade I et déterminer ceux qui sont plus vulnérables à un décès.

ultrasonography. In another randomized controlled trial (7), AFP measurements and ultrasonography revealed a $37 \%$ reduction in HCC mortality.

Early detection of HCC remains critical for long-term survival, and potentially offers more treatment options for patients (8). Currently, surgical resection offers the best chance for cure; however, impaired liver function can present a contraindication to partial hepatectomy $(9,10)$. The known risk factors for HCC enable the identification and screening of at-risk patients; however, less is known about the factors associated with prognosis, which would enable stratification of HCC patients into treatment groups following surgical resection (11). In the present study, the prognostic factors associated with overall survival (OS) and recurrence-free survival (RFS) were analyzed in 140 Taiwanese patients with stage I or stage II small HCC.

\footnotetext{
${ }^{1}$ Department of General Surgery; ${ }^{2}$ Department of Pharmacology; ${ }^{3}$ Department of Radiology; ${ }^{4}$ Laboratory of Biostatistics; ${ }^{5}$ Department of Surgical

Pathology, Changhua Christian Hospital, Changhua; ${ }^{6}$ College of Medicine, Chung Shan Medical University, Taichung, Taiwan

Correspondence and reprints: Dr Yao-Li Chen, Department of General Surgery, Changhua Christian Hospital, 135 Nanhsiao Street, Changhua 500,

Taiwan. Telephone 886-4-7238595 ext 4881, fax 886-4-7230903, e-mail ylchen.cch@gmail.com

Received for publication September 3, 2010. Accepted March 16, 2011
} 
TABLE 1

Demographic and clinical characteristics for all patients according to cancer stage

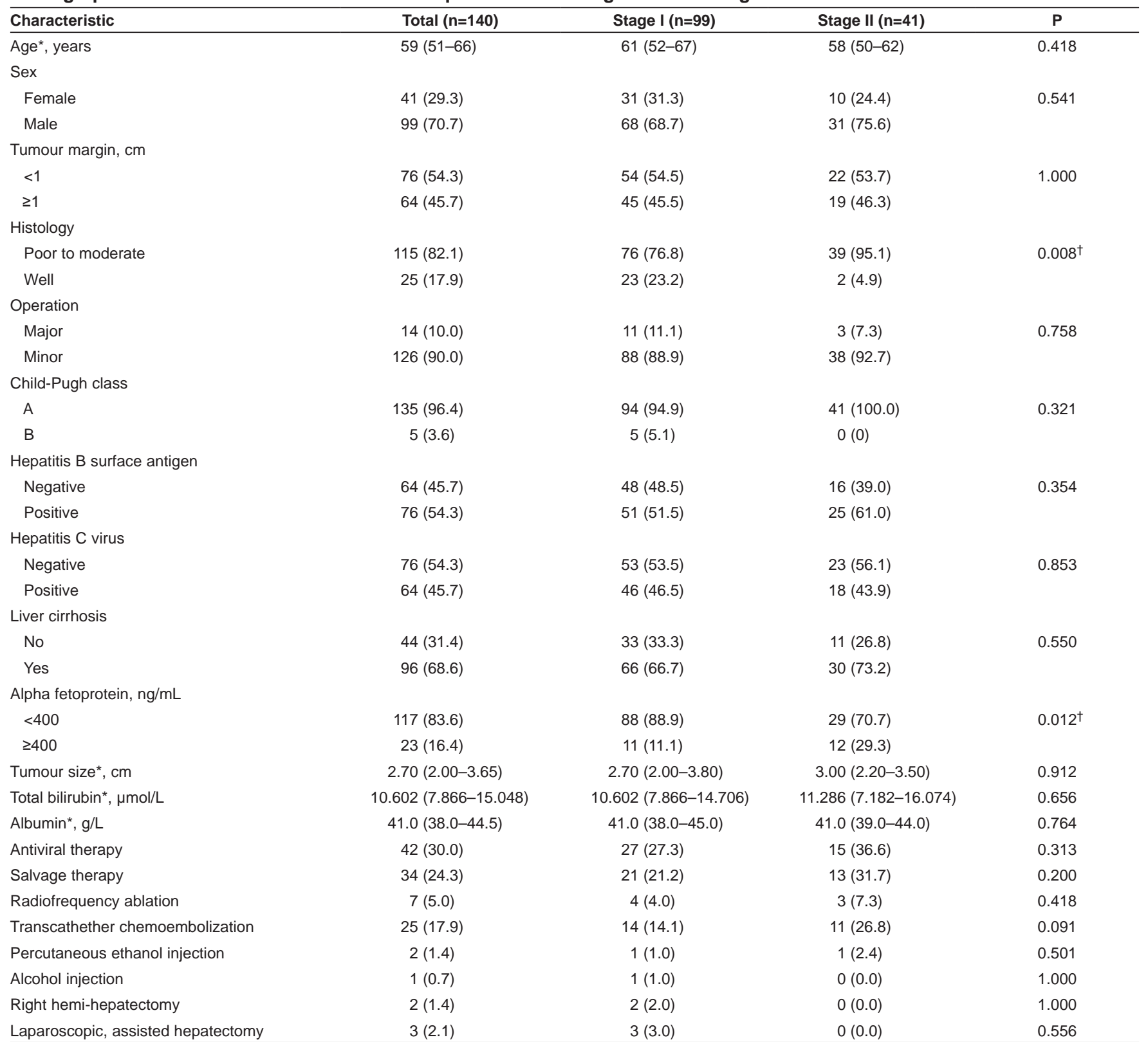

Data presented as $n$ (\%) unless otherwise indicated. ${ }^{*}$ Continuous variable presented as median (interquartile range); ${ }^{\dagger} P<0.05$ indicated a significant association between the corresponding variable and stage

\section{METHODS}

Patient selection

Data were collected from the Changhua Christian Hospital (Taiwan) for all cases of newly diagnosed small HCC surgically treated between January 2001 and December 2007. In the present study, small HCC was defined as tumour(s) $\leq 5 \mathrm{~cm}$ in size. Operations involving the removal of three or more segments of liver were regarded as major hepatectomies; otherwise, these operations were considered to be minor surgeries. A total of 140 consecutive patients with small HCC were enrolled. Following partial hepatectomy, each small HCC case was classified as either stage I or stage II based on the American Joint Committee on Cancer criteria, 6th edition (12). Stage I HCC is defined as a solitary tumour (regardless of size) without vascular invasion. Stage II HCC is defined as either a solitary tumour (regardless of size) with evidence of vascular invasion or multiple tumours, each $<5 \mathrm{~cm}$ in size.

\section{Patient groups}

Table 1 summarizes the demographic data for patients with stage I small HCC $(n=99)$ and stage II small HCC $(n=41)$. The clinical parameters measured included operation type (major or minor hepatectomy), tumour size, tumour histology, Child-Pugh class, HCV status, AFP, total bilirubin and serum albumin levels, the presence of $\mathrm{HBsAg}$ and/or liver cirrhosis, and the administration of antiviral and/or salvage therapy. Child-Pugh class (A, B or C), which is determined by the summation of points assigned to laboratory values (total serum bilirubin and serum albumin levels, and international normalized ratio) and clinical signs (ascites and encephalopathy) in patients with liver disease, can help to predict OS (13).

Follow-up

After partial hepatectomy, patients were followed for a mean of 43.4 months (range 2.6 months to 119.1 months). OS was defined 
TABLE 2

Univariate and multivariate Cox proportional hazard models for death (for all patients and according to cancer stage)

\begin{tabular}{|c|c|c|c|c|c|c|c|c|c|c|}
\hline \multirow{2}{*}{ Characteristic } & \multicolumn{4}{|c|}{ All patients $(n=140)$} & \multirow{2}{*}{\multicolumn{2}{|c|}{$\begin{array}{c}\text { Stage I }(n=99) \\
\text { Univariate }\end{array}$}} & \multicolumn{4}{|c|}{ Stage II $(n=41)$} \\
\hline & \multicolumn{2}{|c|}{ Univariate } & \multicolumn{2}{|c|}{ Multivariate } & & & \multicolumn{2}{|c|}{ Univariate } & \multicolumn{2}{|c|}{ Multivariate } \\
\hline$\overline{\text { Age }}$ & $\begin{array}{c}1.02 \\
(0.99-1.05)\end{array}$ & 0.182 & & & $\begin{array}{c}1.02 \\
(0.98-1.06)\end{array}$ & 0.322 & $\begin{array}{c}1.02 \\
(0.98-1.07)\end{array}$ & 0.306 & & \\
\hline Tumour size & $\begin{array}{c}1.28 \\
(0.95-1.73)\end{array}$ & 0.101 & & & $\begin{array}{c}1.61 \\
(1.10-2.34)\end{array}$ & $0.014^{*}$ & $\begin{array}{c}0.87 \\
(0.54-1.42)\end{array}$ & 0.587 & & \\
\hline $\begin{array}{l}\text { AFP }(\geq 400 \mathrm{ng} / \mathrm{mL} \text { vs } \\
<400 \mathrm{ng} / \mathrm{mL})\end{array}$ & $\begin{array}{c}0.87 \\
(0.34-2.27)\end{array}$ & 0.779 & & & $\begin{array}{c}0.96 \\
(0.22-4.14)\end{array}$ & 0.953 & $\begin{array}{c}0.56 \\
(0.15-2.04)\end{array}$ & 0.375 & & \\
\hline Albumin & $\begin{array}{c}0.57 \\
(0.29-1.10)\end{array}$ & 0.095 & $\begin{array}{c}0.40 \\
(0.19-0.85)\end{array}$ & $0.018^{*}$ & $\begin{array}{c}0.51 \\
(0.23-1.10)\end{array}$ & 0.086 & $\begin{array}{c}0.56 \\
(0.10-3.25)\end{array}$ & 0.521 & & \\
\hline Sex (male vs female) & $\begin{array}{c}2.15 \\
(0.89-5.22)\end{array}$ & 0.090 & $\begin{array}{c}3.00 \\
(1.16-7.75)\end{array}$ & $0.023^{*}$ & $\begin{array}{c}1.58 \\
(0.57-4.38)\end{array}$ & 0.375 & $\begin{array}{c}4.27 \\
(0.55-32.91)\end{array}$ & 0.164 & $\begin{array}{c}7.69 \\
(0.95-62.30)\end{array}$ & 0.056 \\
\hline Operation type (major vs minor) & $\begin{array}{c}0.80 \\
(0.28-2.27)\end{array}$ & 0.670 & & & $\begin{array}{c}1.09 \\
(0.25-4.73)\end{array}$ & 0.906 & $\begin{array}{c}0.39 \\
(0.08-1.77)\end{array}$ & 0.220 & & \\
\hline Child-Pugh class (B vs A) & $\begin{array}{c}2.05 \\
(0.49-8.61)\end{array}$ & 0.327 & & & $\begin{array}{c}2.53 \\
(0.58-11.00)\end{array}$ & 0.216 & NA & & & \\
\hline HBsAg (negative vs positive) & $\begin{array}{c}1.59 \\
(0.80-3.18)\end{array}$ & 0.187 & & & $\begin{array}{c}1.23 \\
(0.51-2.98)\end{array}$ & 0.641 & $\begin{array}{c}2.81 \\
(0.92-8.61)\end{array}$ & 0.070 & $\begin{array}{c}4.06 \\
(1.27-12.95)\end{array}$ & $0.018^{*}$ \\
\hline HCV (positive vs negative) & $\begin{array}{c}1.25 \\
(0.63-2.49)\end{array}$ & 0.525 & & & $\begin{array}{c}1.18 \\
(0.48-2.87)\end{array}$ & 0.718 & $\begin{array}{c}1.42 \\
(0.48-4.23)\end{array}$ & 0.530 & & \\
\hline Cirrhosis (present vs absent) & $\begin{array}{c}1.06 \\
(0.47-2.36)\end{array}$ & 0.891 & & & $\begin{array}{c}1.11 \\
(0.40-3.08)\end{array}$ & 0.846 & $\begin{array}{c}0.81 \\
(0.22-2.98)\end{array}$ & 0.746 & & \\
\hline Microvascular invasion & $\begin{array}{c}1.27 \\
(0.53-3.00)\end{array}$ & 0.590 & & & NA & & $\begin{array}{c}0.58 \\
(0.15-2.24)\end{array}$ & 0.427 & & \\
\hline
\end{tabular}

Variables with $P<0.1$ in the corresponding univariate Cox proportional hazard models were selected for the multivariate model by the forward conditional method. ${ }^{*} P<0.05$ indicated that the $95 \% \mathrm{Cl}$ of HR did not include 1. AFP Alpha-fetoprotein; HBsAg Hepatitis B surface antigen; HCV Hepatitis C virus; NA Not available due to zero patients who were classified as Child-Pugh B in the stage II group, and zero patients with microvascular invasion and multifocality in the stage I group; vs Versus

as the time from surgery to death. RFS was defined as the time from surgery to the diagnosis of cancer recurrence.

\section{Statistical analysis}

A non-normal distribution was demonstrated for all continuous variables, which were summarized as median and interquartile range. The Mann-Whitney test was performed to compare the continuous variables between patients in the stage I and stage II groups. Categorical variables were summarized according to absolute count and percentage, and were analyzed using the Fisher's exact test. Kaplan-Meier survival curves were used to predict OS and RFS. The log-rank test was used to compare the Kaplan-Meier survival curves for patients with stage I and stage II small HCC. Univariate and multivariate Cox proportional hazard models were performed to assess the prognostic factors for OS and RFS, and were summarized as the HR and corresponding 95\% CI. Variables with $\mathrm{P}<0.1$ in the corresponding univariate Cox proportional hazard models were selected for the multivariate model using the forward conditional method. Statistical analyses were performed using SPSS version 15.0 (IBM Corporation, USA) for Windows (Microsoft Corporation, USA). $\mathrm{P}<0.05$ was considered to be statistically significant.

\section{RESULTS}

Demographic and clinical findings for all patients and for those with stage I and stage II HCC are presented in Table 1 . Of the 140 patients, $41(29.3 \%)$ were female and $99(70.7 \%)$ were male, with a median age of 59 years. Patients with stage II small HCC were more likely to present with an AFP level of $\geq 400 \mathrm{ng} / \mathrm{mL} \quad(P=0.012)$ and to have tumours demonstrating poorly to moderately differentiated histological grades than were patients with stage I small HCC $(\mathrm{P}=0.008)$. However, no significant associations were observed with respect to age, sex, tumour margins, operation type, Child-Pugh class, presence of HBsAg, HCV status, presence of liver cirrhosis, tumour size, total serum bilirubin and serum albumin levels, antiviral therapy or salvage therapies (all $\mathrm{P}>0.05$ ).

The Cox proportional hazard models for OS for all patients in the present study are summarized in Table 2 . No significant factors associated with $O S$ were identified in this group of 140 patients $(P>0.05)$. After model selection using the forward conditional method, albumin level and sex were selected for the multivariate Cox proportional hazard model. For each unit $(10 \mathrm{~g} / \mathrm{L})$ increase in the albumin level, the HR decreased by a factor of 0.40 (95\% CI 0.19 to $0.85 ; \mathrm{P}=0.018)$. 
TABLE 3

Univariate and multivariate Cox proportional hazard models for recurrence (for all patients and according to cancer stage)

\begin{tabular}{|c|c|c|c|c|c|c|c|c|}
\hline \multirow{2}{*}{ Characteristic } & \multicolumn{4}{|c|}{ All patients $(n=140)$} & \multirow{2}{*}{\multicolumn{2}{|c|}{$\begin{array}{c}\text { Stage I }(\mathbf{n = 9 9 )} \\
\text { Univariate }\end{array}$}} & \multirow{2}{*}{\multicolumn{2}{|c|}{$\begin{array}{c}\text { Stage II }(n=41) \\
\text { Univariate }\end{array}$}} \\
\hline & \multicolumn{2}{|l|}{ Univariate } & \multicolumn{2}{|l|}{ Multivariate } & & & & \\
\hline Age & $1.03(1.00-1.05)$ & $0.023^{*}$ & $1.03(1.01-1.05)$ & $0.016^{*}$ & $1.03(1.00-1.07)$ & $0.024 *$ & $1.01(0.98-1.05)$ & 0.532 \\
\hline AFP level ( $\geq 400 \mathrm{ng} / \mathrm{L}$ vs $<400 \mathrm{ng} / \mathrm{L})$ & $0.96(0.49-1.89)$ & 0.901 & & & $0.98(0.35-2.77)$ & 0.974 & $0.71(0.27-1.84)$ & 0.482 \\
\hline Total bilirubin & $1.02(0.48-2.15)$ & 0.961 & & & $0.90(0.31-2.63)$ & 0.850 & $1.10(0.40-2.97)$ & 0.856 \\
\hline Tumour margin $(\geq 1 \mathrm{~cm}$ vs $<1 \mathrm{~cm})$ & $0.69(0.41-1.15)$ & 0.153 & & & $0.63(0.33-1.23)$ & 0.175 & $0.70(0.30-1.65)$ & 0.418 \\
\hline Histology (moderate-poor vs well) & $0.58(0.27-1.21)$ & 0.145 & & & $0.54(0.23-1.29)$ & 0.167 & $1.19(0.25-5.63)$ & 0.822 \\
\hline Operation (major vs minor) & $1.31(0.52-3.27)$ & 0.565 & & & $1.06(0.38-2.99)$ & 0.913 & $1.86(0.25-13.87)$ & 0.543 \\
\hline Child-Pugh class (B vs A) & $1.50(0.47-4.79)$ & 0.496 & & & $1.76(0.54-5.75)$ & 0.346 & NA & - \\
\hline HBsAg (negative vs positive) & $1.16(0.70-1.91)$ & 0.571 & & & $1.21(0.64-2.29)$ & 0.551 & $1.09(0.48-2.49)$ & 0.841 \\
\hline Antiviral therapy & $0.81(0.46-1.43)$ & 0.460 & & & $0.76(0.36-1.60)$ & 0.469 & $0.79(0.32-1.92)$ & 0.596 \\
\hline Stage II vs stage I & $1.75(1.04-2.93)$ & $0.036^{*}$ & $1.78(1.06-2.99)$ & $0.030^{*}$ & - & - & - & - \\
\hline
\end{tabular}

Variables with $P<0.1$ in the corresponding univariate Cox proportional hazard models were selected for the multivariate model by the forward conditional method. ${ }^{*} P<0.05$ indicated that the $95 \% \mathrm{Cl}$ of HR did not include 1. AFP Alpha-fetoprotein; HBsAg Hepatitis B surface antigen; HCV Hepatitis C virus; NA Not available due to zero patients who were Child-Pugh B in the stage II group; vs Versus

TABLE 4

The association between liver cirrhosis and hepatitis B status

\begin{tabular}{|c|c|c|c|c|c|c|c|c|c|c|}
\hline & & \multicolumn{3}{|c|}{ Total $(n=140)$} & \multicolumn{3}{|c|}{ Stage I ( $n=99)$} & \multicolumn{3}{|c|}{ Stage II $(n=41)$} \\
\hline & & HBsAg+ & HBsAg- & & HBsAg+ & HBsAg- & & HBsAg+ & HBsAg- & \\
\hline & & $(n=76)$ & $(n=64)$ & $\mathbf{P}$ & $(n=51)$ & $(n=48)$ & $\mathbf{P}$ & $(n=25)$ & $(n=16)$ & $\mathbf{P}$ \\
\hline Liver cirrhosis & Yes & 55 (72.4) & $41(64.1)$ & 0.361 & $36(70.6)$ & $30(62.5)$ & 0.261 & $19(76.0)$ & $11(68.8)$ & 0.436 \\
\hline \multirow[t]{2}{*}{ Antiviral therapy } & Yes & 41 (53.9) & $1(1.6)$ & $<0.001^{*}$ & $26(51.0)$ & $1(2.1)$ & $<0.001^{\star}$ & $15(60.0)$ & $0(0.0)$ & $<0.001^{*}$ \\
\hline & No & $35(46.1)$ & $63(98.4)$ & & $25(49.0)$ & 47 (97.9) & & $10(40.0)$ & $16(100.0)$ & \\
\hline
\end{tabular}

Data presented as $n(\%)$ unless otherwise indicated. ${ }^{*} P<0.05$ indicated a significant association between the corresponding variable and cancer stage. HBsAg+ Hepatitis $B$ surface antigen positive; $H B S A g$ hepatitis $B$ surface antigen negative

Male patients had a significantly higher risk of death than female patients (HR 3.00 [95\% CI 1.16 to 7.75]; P=0.023).

The Cox proportional hazard models for OS for patients with stage I and stage II disease are also presented in Table 2. For the 99 patients with stage I small HCC, only tumour size reached statistical significance $(\mathrm{P}=0.014)$. No significant factors were found to be associated with death in patients with stage II small HCC using the univariate Cox proportional hazard models $(P>0.05)$. Sex, tumour margin and the presence of HBsAg for stage II small HCC were then included in the multivariate Cox model, with only the presence/absence of $\mathrm{HBs} \mathrm{Ag}$ reaching statistical significance $(\mathrm{P}=0.018)$. In patients with stage II small HCC, the absence of $\mathrm{HBsAg}$ was associated with a higher risk of death compared with the presence of HBsAg (HR 4.06 [95\% CI 1.27 to 12.95$] ; \mathrm{P}=0.018)$. Of the patients with stage II disease, $34(82.9 \%)$ and $12(29.3 \%)$ demonstrated microvascular invasion and multifocality, respectively. When these variables were included in the survival analysis, no significant effect on survival was observed.

Table 3 summarizes RFS for all patients in the study. For these 140 patients, age and tumour stage were identified as significant factors in RFS in the univariate Cox proportional hazard models. Age, sex and tumour stage were included in the multivariate Cox model, but only age and tumour stage remained statistically significant. For each year increase in age, the risk of cancer recurrence increased by a factor of 1.03 ( $95 \%$ CI 1.00 to $1.05 ; \mathrm{P}=0.016$ ).
RFS findings for patients with stage I and stage II small HCC are also found in Table 3. A significantly higher risk of recurrence was demonstrated for patients with stage II compared with stage I small HCC (HR 1.78 [95\% CI 1.06 to 2.99]; $\mathrm{P}=0.030$ ). Among patients with stage I small HCC, only age reached statistical significance in the corresponding univariate Cox proportional hazard model. For each year increase in age, the risk of recurrence in those with stage I small HCC increased by a factor of 1.03 (95\% CI 1.00 to $1.07 ; \mathrm{P}=0.024$ ). Among patients with stage II small HCC, no factors potentially associated with cancer recurrence reached statistical significance when analyzed in univariate or multivariate Cox proportional hazard models.

Seventy-six patients were $\mathrm{HBsAg}$ positive, while 64 were $\mathrm{HBsAg}$ negative. The proportion of patients with cirrhosis were $72.4 \%$ and $64.1 \%$, respectively, without a significant difference $(\mathrm{P}=0.361)$. The proportion of patients who underwent antiviral therapy and were HBs Ag positive $(53.9 \%)$ was significantly greater than those who were HBsAg negative $(1.6 \%)(\mathrm{P}<0.001)$. Similar results were observed after stratification according to HCC stage (Table 4).

Kaplan-Meier OS and RFS curves for all 140 patients with small HCC are shown in Figure 1. The OS at three years was $87.4 \%$, and at five years was $78.6 \%$ (left panel). The RFS at three years was $67.3 \%$, and at five years was $50.5 \%$ (right panel).

Kaplan-Meier OS and RFS curves for stage I and stage II small HCC are shown in Figure 2. Compared with patients with stage I small HCC, 


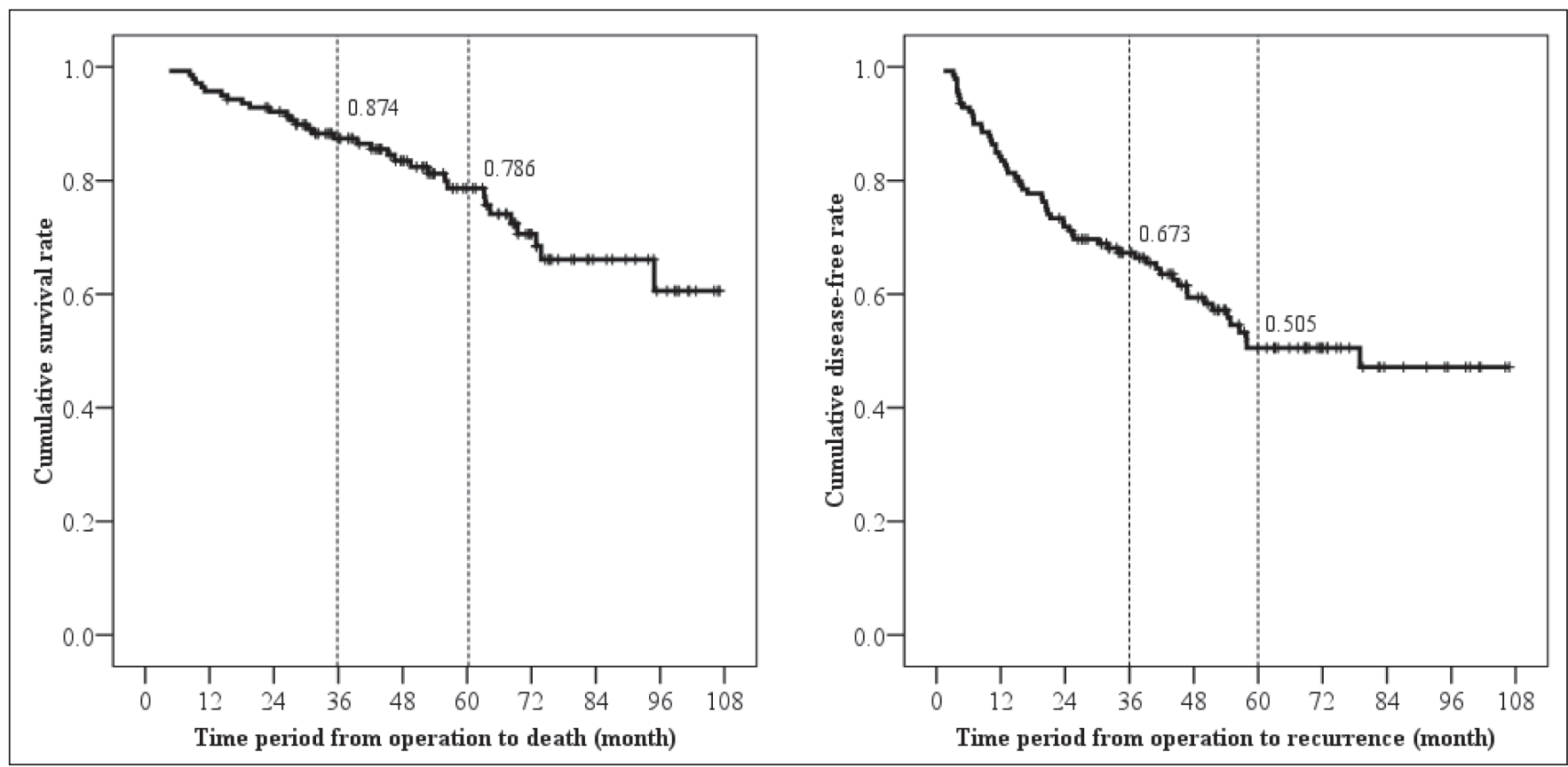

Figure 1) Overall survival and recurrence-free survival rates for 140 patients with small hepatocellular carcinoma who underwent hepatic resection. The threeand five-year overall survival rates were $87.4 \%$ and $78.6 \%$, respectively (left panel). The three-and five-year recurrence-free survival rates were $67.3 \%$ and $50.5 \%$, respectively (right panel)

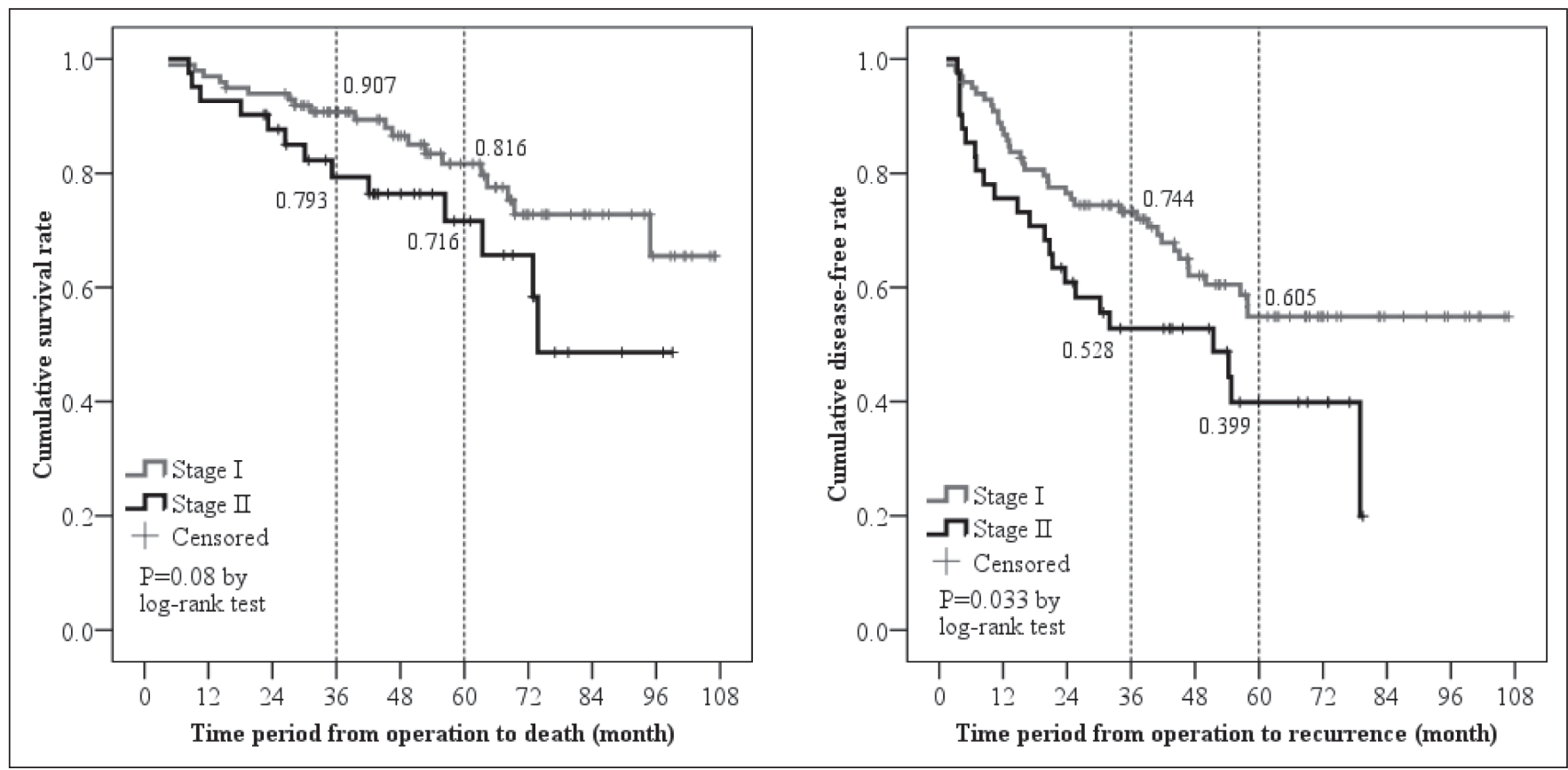

Figure 2) Overall survival rate and recurrence-free survival rate for stage I and stage II small hepatocellular carcinoma (HCC) patients. The difference in overall survival rate between stage I and stage II HCC patients did not reach statistical significance $(P=0.08$ [left panel]). The recurrence-free survival rate for patients with stage II small HCC was significantly poorer than those with stage I small HCC $(P=0.033$ [right panel])

patients with stage II small HCC experienced poorer OS (left panel) and RFS (right panel). For stage I small HCC, the OS at three years was $90.7 \%$, and at five years was $81.6 \%$. For stage II small HCC, the OS at three years was $79.3 \%$ and at five years was $71.6 \%$. However, the difference in OS at either time between the two groups was not statistically significant $(\mathrm{P}=0.08)$. In contrast, the differences in RFS at three and five years between patients with stage I and stage II small HCC were significant $(\mathrm{P}=0.033)$. For stage I small HCC, the RFS at three years was $74.4 \%$, and at five years was $60.5 \%$, whereas for stage II small HCC, the RFS was $52.8 \%$ at three years and $39.9 \%$ at five years.

\section{DISCUSSION}

In patients with HCC, increasing tumour size has generally been associated with poorer prognoses $(10,14-17)$. The present study verified the relationship between small tumour size in HCC and OS; however, a reduction in OS with increasing tumour size was demonstrated only for stage I small HCC (not for stage II small HCC). By definition, stage I small $\mathrm{HCC}$ includes tumours up to $5 \mathrm{~cm}$ in size, and an increase in tumour size in small HCC has been shown in several studies to directly correlate with an increased risk of vascular invasion. In patients with stage I small HCC who had larger tumours, the OS and RFS may 
be closer to those seen with stage II small HCC. Compared with patients with stage I small HCC, patients with stage II small HCC demonstrated poorer OS and RFS. Although the difference in RFS, but not in OS, was statistically significant, the trend toward improved survival in patients with tumours without evidence of microscopic invasion is clear.

Several clinicopathological risk factors were identified in the current study. For all 140 small HCC patients, older age and male sex were significantly associated with an increased risk of cancer recurrence and death, respectively. The immune system may weaken with advancing age, thereby reducing the quality of surveillance for tumour recurrence. Other comorbidities may also be involved with advancing age. Higher albumin levels, reflective of better overall liver function, were significantly associated with a decreased risk of death. AFP levels $\geq 400 \mu \mathrm{g} / \mathrm{L}$ were significantly more likely to be associated with stage II small HCC, indicative of more aggressive tumours with vascular invasion. Stage II small HCC histological grades generally indicated more poorly or moderately differentiated tumours compared with stage I small HCC histological grades. Furthermore, in patients with stage II small HCC, the absence - compared with the presence - of HBsAg was associated with a higher risk of death. As shown in Table 2, the HR for patients without HBV infection versus with those with HBV infection was $4.06(\mathrm{P}=0.018)$. Considering that HBV infection is a risk factor for HCC, this surprising finding warrants further study. We further assessed the relationship between HBV infection and cirrhosis status, and confirmed that the majority of the HBsAg-negative patients with stage II small HCC were cirrhotic, while the majority of $\mathrm{HBsAg}$ positive patients with stage II small HCC were noncirrhotic. In the present study, 76 stage I HCC patients were $\mathrm{HBs}$ Ag positive and 64 were $\mathrm{HBsAg}$ negative. The proportions of patients with and without cirrhosis were $72.4 \%$ and $64.1 \%$, respectively, without a significant difference $(P=0.361)$. For stage II HCC patients $(n=41)$, 25 patients were $\mathrm{HBsAg}$ positive and 16 were $\mathrm{HBsAg}$ negative. The proportions of patients with and without cirrhosis were $76.0 \%$ and $68.8 \%$, respectively, without significant difference $(\mathrm{P}=0.436)$. In this regard, it was also of interest to determine the percentage of $\mathrm{HBsAg}$ positive patients with stage II small HCC who received antiviral therapy. The proportions of patients who received and did not receieve antiviral therapy were $60.0 \%$ and $0 \%$, respectively - a statistically significant difference $(\mathrm{P}<0.001)$. This finding suggests a reasonable explanation; however, the actual reason needs further evaluation.

The reported OS rates for patients with HCC following resection varies widely in the literature, with five-year OS rates ranging from $35 \%$ to $70 \%(18-20)$. Different staging systems and criteria may account for the disparate outcomes. Data from our study reveal that even patients with early HCC can be stratified into subgroups with distinct long-term prognoses. In the multivariate analysis of the stage I group, only tumour size demonstrated a significant association with OS. Tumour margins, tumour histology, and the presence or absence of cirrhosis did not influence OS for patients with either stage I or stage II small HCC. In the current study, only patients with tumours $\leq 5 \mathrm{~cm}$ in size were included, and the mean tumour sizes for stage I and stage II small HCC were $2.7 \mathrm{~cm}$ and $3.0 \mathrm{~cm}$, respectively. The incidence of vascular invasion has been reported to increase with tumour size in several studies $(11,14,15)$. However, even microscopic vascular invasion has been shown to be related to poorer OS in patients with small HCC $(11,14)$. In the present study, $82 \%$ of patients with stage II small HCC had tumours with vascular invasion, with the remaining $18 \%$ presenting with multifocal lesions. Zhou et al (8) reported a decrease in OS that was significantly associated with tumour size; the fiveyear OS rates for patients with small HCC tumours $\leq 2 \mathrm{~cm}, 2.1 \mathrm{~cm}$ to $3.0 \mathrm{~cm}$, and $3.1 \mathrm{~cm}$ to $5.0 \mathrm{~cm}$ in size were $82.5 \%, 66.3 \%$ and $61.2 \%$, respectively $(\mathrm{P}<0.05)$. However, Nanashima et al $(21)$ reported no significant difference in OS between solitary small HCC tumours $<2 \mathrm{~cm}$ and those $2 \mathrm{~cm}$ to $3 \mathrm{~cm}$ in size. In another study, the five-year OS for small HCC tumours between $2 \mathrm{~cm}$ and $5 \mathrm{~cm}$ was found to be $43 \%$
(10). Lu et al (17) observed no significant difference in OS or RFS between tumours measuring $1.1 \mathrm{~cm}$ to $2 \mathrm{~cm}$, and $2.1 \mathrm{~cm}$ to $3 \mathrm{~cm}$ in size. These investigators reported that a tumour size of $<3 \mathrm{~cm}$ was associated with a better prognosis and suggested that $3 \mathrm{~cm}$ represents the optimum size for designation of an HCC tumour as small.

RFS rates of between $35 \%$ and $75 \%$ have been reported for small HCC (22-25). Wang et al (26) reported that the three- and five-year RFS rates following surgical resection for small HCC tumours $<3 \mathrm{~cm}$ in size were $49 \%$ and $30 \%$, respectively. In our stage I small HCC patients, three- and five-year RFS rates were $71.19 \%$ and $50.93 \%$, respectively, and three- and five-year disease-specific survival rates were $92.23 \%$ and $82.65 \%$, respectively. In stage II small HCC patients, three- and five-year RFS rates were $49.33 \%$ and $35.97 \%$, respectively, and three- and five-year disease-specific survival rates were $79.00 \%$ and $79.00 \%$, respectively.

For patients with stage II small HCC (who demonstrated a significantly higher risk of cancer recurrence than those with stage I small $\mathrm{HCC}$ ), a second surgical resection was performed if the reserve liver function and anatomical pathology permitted. Salvage therapy for recurrent lesions includes transcatheter arterial chemoembolization, radiofrequency ablation, percutaneous ethanol injection and orthotopic liver transplantation $(27,28)$. Three-year and five-year diseasespecific survival rates support the effectiveness of salvage therapy; however, further study is needed to confirm survival benefit of this particular therapy.

Limitations inherent to the current study included the relatively small number of patients and a lack of standardization with respect to the follow-up period. Compared with some studies, 140 appears to be a significant sample size; however, additional studies with greater numbers of patients may result in more targeted survival rates. Because some patients were followed for only two to three months, longer follow-up periods might provide further clarification regarding other factors affecting OS and RFS. Additionally, the present study was limited to Taiwanese patients and may not reflect small HCC behaviour in other ethnic groups.

\section{CONCLUSION}

The present study of patients with small HCC treated with surgical resection revealed that tumour stage II was associated with an increased risk of cancer recurrence, and that tumour size was associated with an increased risk of death in patients with stage I HCC Additional studies are needed to clarify the relationship between tumour size and overall prognosis. Aggressive salvage therapy may benefit patients in the stage II group such that their overall diseasespecific survival is improved.

ACKNOWLEDGEMENTS: The authors thank the Tumor Center of Changhua Christian Hospital (Taiwan) and Ms Chi-Fang Cheng for their great assistance and involvement in this study.

\section{REFERENCES}

1. Parkin DM. Global cancer statistics in the year 2000. Lancet Oncol 2001;2:533-43.

2. Jan CF, Chen CJ, Chen HH. Causes of increased mortality from hepatocellular carcinoma in high incidence country:

Taiwan experience. J Gastroenterol Hepatol 2005;20:521-6.

3. Ferlay J, Shin HR, Bray F, Forman D, Mathers C, Parkin DM. Estimates of worldwide burden of cancer in 2008: GLOBOCAN 2008. Int J Cancer 2010;127:2893-917.

4. Cabibbo G, Craxì A. Epidemiology, risk factors and surveillance of hepatocellular carcinoma. Eur Rev Med Pharmacol Sci 2010;14:352-5.

5. Fehér J, Lengyel G. Hepatocellular carcinoma: Occurrence, risk factors, biomarkers. Orv Hetil 2010;151:933-40. 
6. Chen THH, Chen CJ, Yen MF, et al. Ultrasound screening and risk factors for death from hepatocellular carcinoma in a high risk group in Taiwan. Int J Cancer 2002;98:257-61.

7. Zhang BH, Yang BH, Tang ZY. Randomized controlled trial of screening for hepatocellular carcinoma. J Cancer Res Clin Oncol 2004;130:417-22.

8. Zhou XD, Tang ZY, Yang BH, et al. Experience of 1000 patients who underwent hepatectomy for small hepatocellular carcinoma. Cancer 2001;91:1479-86.

9. Yamamoto M, Takasaki K, Otsubo T, et al. Favorable surgical outcomes in patients with early hepatocellular carcinoma. Ann Surg 2004:239:395-9.

10. Ochiai T, Sonoyama T, Ichikawa D, et al. Poor prognostic factors of hepatectomy in patients with resectable small hepatocellular carcinoma and cirrhosis. J Cancer Res Clin Oncol 2004;130:197-202.

11. Nathan H, Schulick RD, Choti MA, et al. Predictors of survival after resection of early hepatocellular carcinoma. Ann Surg 2009;249:799-805

12. American Joint Committee on Cancer. Comparison Guide: Cancer Staging Manual. Fifth versus Sixth Edition. <www.cancerstaging.org/products/ajccguide.pdf> (Accessed on July 12, 2011).

13. Riley TR, Bhatti A. Preventative strategies in chronic liver disease: Part II. cirrhosis. Am Fam Phys 2001;64:1735-41.

14. Tsai TJ, Chau GY, Lui WY, et al. Clinical significance of microscopic tumor venous invasion in patients with resectable hepatocellular carcinoma. Surgery 2000;127:603-8.

15. Pawlik TM, Delman KA, Vauthey JN, et al. Tumor size predicts vascular invasion and histologic grade: Implications for selection of surgical treatment for hepatocellular carcinoma. Liver Transpl 2005;11:1086-92.

16. Llovet JM, Bru C, Bruix J. Prognosis of hepatocellular carcinoma: The BCLC staging classification. Semin Liver Dis 1999;19:329-38.

17. Lu XY, Xi T, Lau WY, et al. Pathobiological features of small hepatocellular carcinoma: Correlation between tumor size and biological behavior. J Cancer Res Clin Oncol 2011;137:567-75.
18. Bruix J, Llovet JM. Prognostic prediction and treatment strategy in hepatocellular carcinoma. Hepatology 2002;35:519-24.

19. Fuster J, Garcia-Valdecasas JC, Grande L, et al. Hepatocellular carcinoma and cirrhosis. Results of surgical treatment in a European series. Ann Surg 1996;223:297-302.

20. Franco D, Capussotti L, Smadja C, et al. Resection of hepatocellular carcinomas: Results in 72 European patients with cirrhosis. Gastroenterology 1990;98:733-8.

21. Nanashima A, Tobinaga S, Masuda J, et al. Selecting treatment for hepatocellular carcinoma based on the results of hepatic resection and local ablation therapy. J Surg Oncol 2010;101:481-5.

22. Tanaka S, Noguchi N, Ochiai T, et al. Outcomes and recurrence of initially resectable hepatocellular carcinoma meeting Milan criteria: Rationale for partial hepatectomy as first strategy. J Am Coll Surg 2007;204:1-6.

23. Hwang S, Lee SG, Moon DB, et al. Salvage living donor liver transplantation after prior liver resection for hepatocellular carcinoma. Liver Transpl 2007;13:741-6.

24. Sasaki Y, Yamada T, Tanaka H. Risk of recurrence in a long-term follow-up after surgery in 417 patients with hepatitis B- or hepatitis C-related hepatocellular carcinoma. Ann Surg 2006;244:771-80.

25. Tung-Ping Poon R, Fan ST, Wong J. Risk factors, prevention, and management of postoperative recurrence after resection of hepatocellular carcinoma. Ann Surg 2000;232:10-24.

26. Wang ZL, Liang P, Dong BW, Yu XL, Yu de J. Prognostic factors and recurrence of small hepatocellular carcinoma after hepatic resection or microwave ablation: A retrospective study. J Gastrointest Surg 2008;12:327-37.

27. Poon RT, Fan ST, Lo CM, Liu CL, Wong J. Long-term survival and pattern of recurrence after resection of small hepatocellular carcinoma in patients with preserved liver function: Implications for a strategy of salvage transplantation. Ann Surg 2002;235:373-82.

28. Cabibbo G, Latteri F, Antonucci M, Craxì A. Multimodal approaches to the treatment of hepatocellular carcinoma. Nat Clin Pract Gastroenterol Hepatol 2009;6:159-69. 


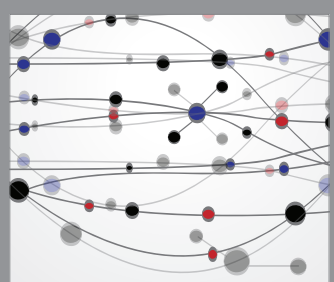

The Scientific World Journal
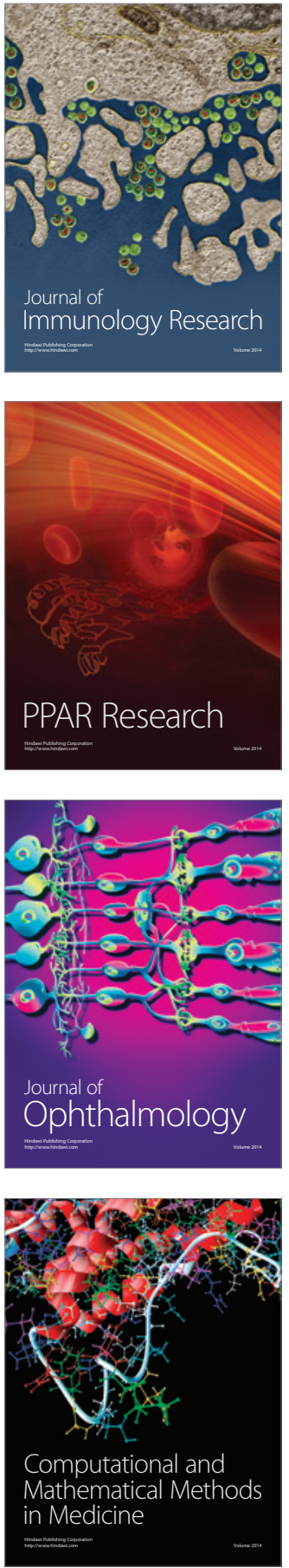

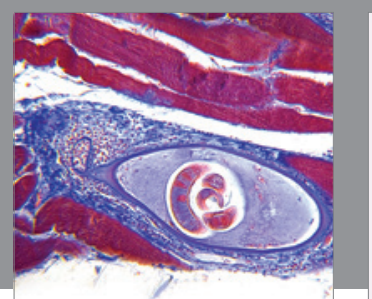

Gastroenterology Research and Practice

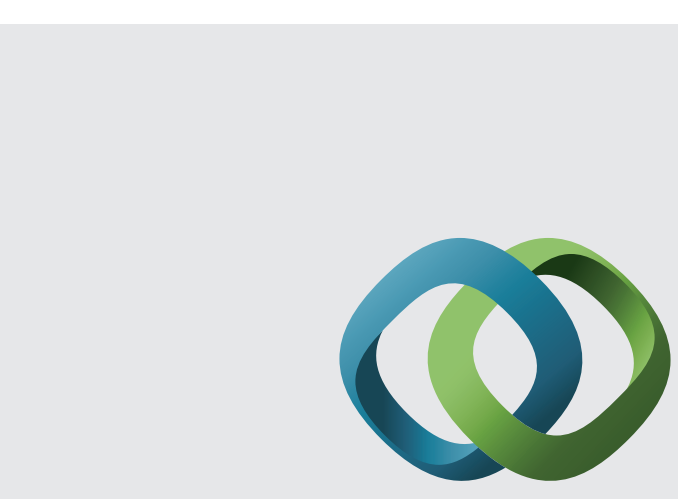

\section{Hindawi}

Submit your manuscripts at

http://www.hindawi.com
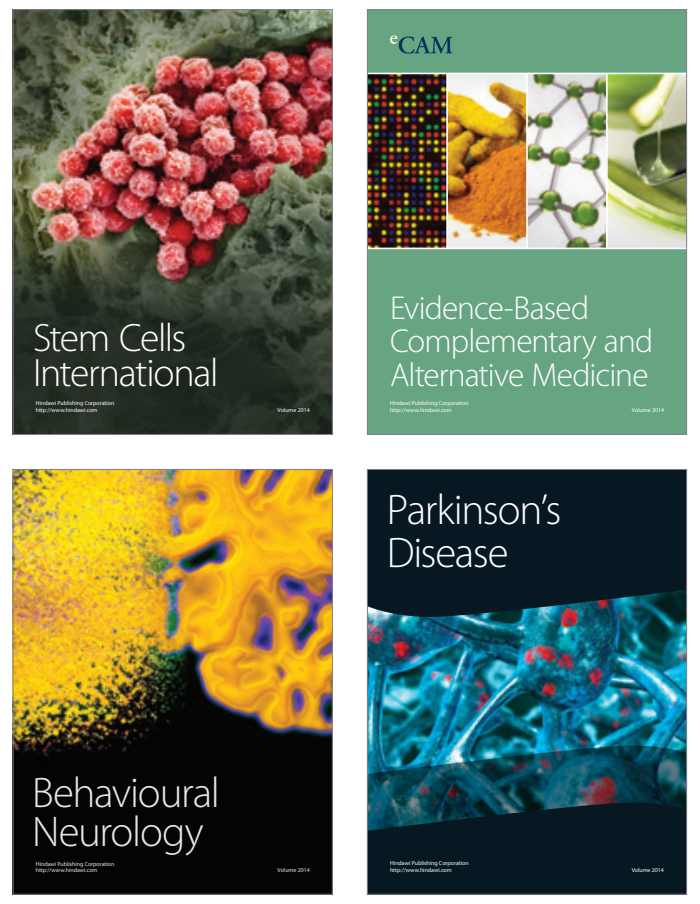
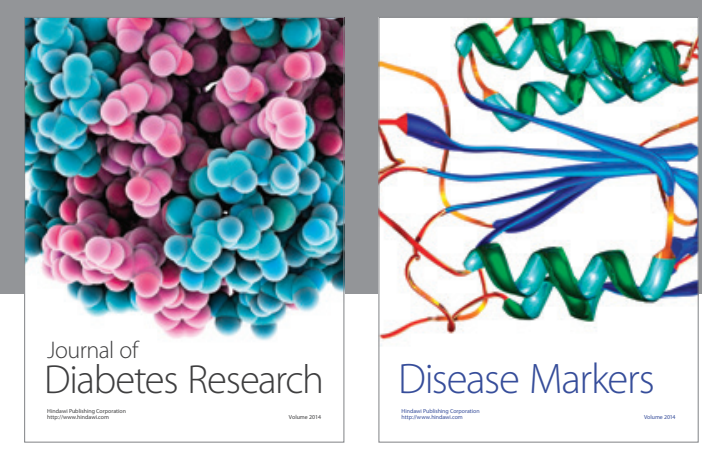

Disease Markers
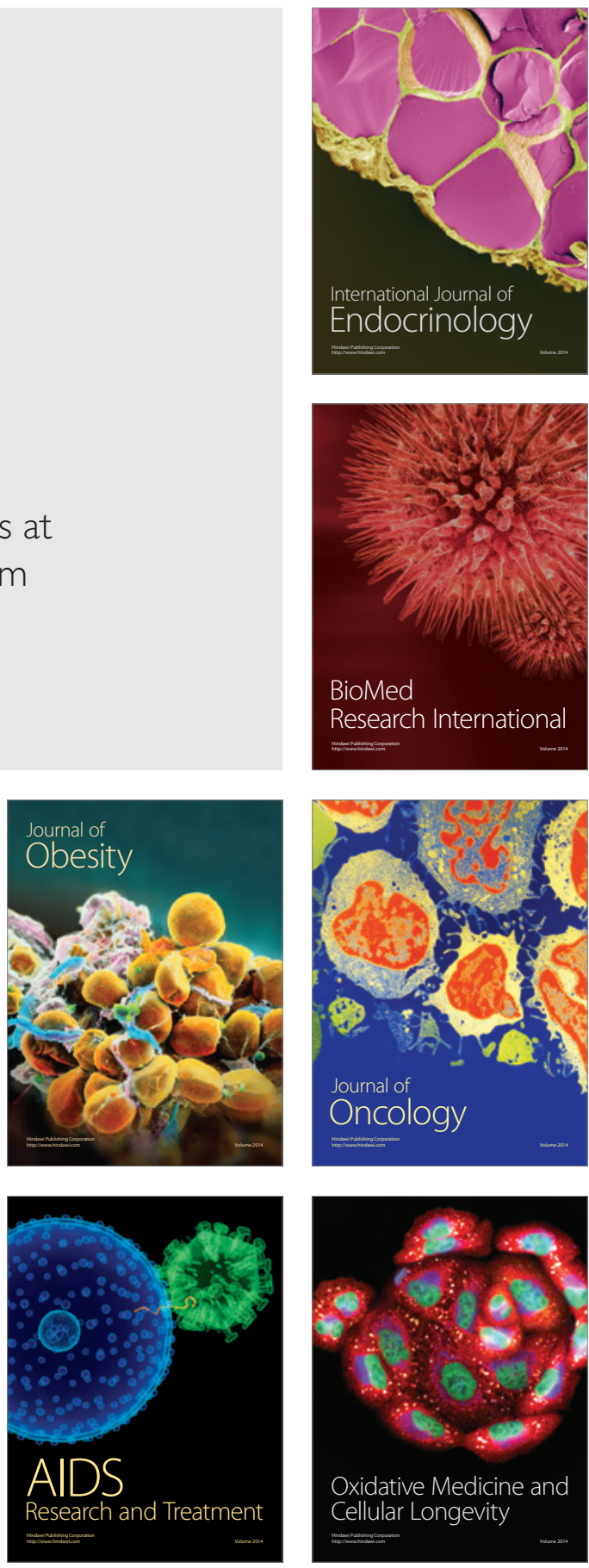